\title{
First intermediate hosts of Paragonimus spp. in Vietnam and identification of intramolluscan stages of different Paragonimus species
}

Pham Ngoc Doanh ${ }^{1,2^{*}}$, Luu Anh Tu², Hoang Van Hien ${ }^{1}$, Nguyen Van Duc ${ }^{1}$, Yoichiro Horii ${ }^{3}$, David Blair ${ }^{4}$ and Yukifumi Nawa ${ }^{5}$

\begin{abstract}
Background: Members of the genus Paragonimus require at least three hosts in their life-cycles. The obligatory first intermediate hosts are freshwater snails. In Vietnam, although seven Paragonimus species have been recorded, the natural first intermediate hosts of almost all species have not been confirmed. The aim of this study was, therefore, to investigate snail hosts of Paragonimus species in Vietnam, and to identify Paragonimus species at intramolluscan stages.

Methods: Freshwater snails were collected from streams in Yen Bai and Quang Tri Provinces, where high prevalences of Paragonimus metacercariae in crab hosts have been reported. Snails were morphologically identified and then examined individually for Paragonimus cercariae using shedding and crushing methods.

Chaetomicrocercous cercariae, the morphological class to which Paragonimus cercariae belong, were collected for morphological description and molecular species identification by analyses of ITS2 sequences. The infected snail species were identified based on analyses of nucleotide sequences of the cox1 gene.

Results: Three snail species were found to be infected with Paragonimus cercariae at low infection rates, ranging between $0.07-1.0 \%$. The molecular analyses identified them as Sulcospira quangtriensis and 2 species of subfamily Triculinae. In a phylogenetic tree, these two triculine snails were related to the genera Gammatricula and Tricula with low posterior probabilities. Thus we named them as Triculinae sp. 1 and Triculinae sp. 2. Cercariae from the three snail species, Sulcospira quangtriensis, Triculinae sp. 1 and Triculinae sp. 2, were molecularly identified as Paragonimus westermani, P. heterotremus and P. proliferus, respectively. The cercariae of the three species are morphologically similar to each other, but their daughter rediae can be distinguished by the length of the intestine and the number of cercariae per redia. The rediae of $P$. westermani have a long intestine and each contain 6-8 cercariae. In contrast, those of $P$. heterotremus and $P$. proliferus have a short intestine and each redia contain 10-12 and 5-6 cercariae, respectively.

Conclusions: Three snail species, Sulcospira quangtriensis, Triculinae sp. 1 and Triculinae sp. 2, serve as the first intermediate hosts of $P$. westermani, P. heterotremus and P. proliferus, respectively, in Vietnam. The length of the intestine of rediae and the number of cercariae per redia are valuable characteristics for distinguishing between larvae of these Paragonimus species.
\end{abstract}

Keywords: First intermediate host, Paragonimus, Sulcospira quangtriensis, Triculinae

\footnotetext{
* Correspondence: pndoanh@yahoo.com

'Institute of Ecology and Biological Resources, Viet Nam Academy of Science

and Technology, Hanoi, Viet Nam

${ }^{2}$ Graduate University of Science and Technology, Viet Nam Academy of

Science and Technology, Hanoi, Viet Nam

Full list of author information is available at the end of the article
}

(c) The Author(s). 2018 Open Access This article is distributed under the terms of the Creative Commons Attribution 4.0 International License (http://creativecommons.org/licenses/by/4.0/), which permits unrestricted use, distribution, and reproduction in any medium, provided you give appropriate credit to the original author(s) and the source, provide a link to the Creative Commons license, and indicate if changes were made. The Creative Commons Public Domain Dedication waiver (http://creativecommons.org/publicdomain/zero/1.0/) applies to the data made available in this article, unless otherwise stated. 


\section{Background}

Lung flukes of the genus Paragonimus (Family Paragonimidae) are parasites of mammals, commonly cats and canids, and occasionally humans. Members of this genus require at least three different hosts to complete their life-cycles [1]. The first intermediate hosts are freshwater snails in which the flukes develop through several stages (sporocyst, mother and daughter rediae, and cercariae). The cercariae belong to the microcercous type (subtype chaetomicrocercous), possessing an anterior stylet, a knob-like tail, spines on the body and tail, but lacking unicellular glands [2]. Mature cercariae escape from the snail hosts and penetrate suitable crab/crayfish hosts to develop into an infective stage, metacercariae. Definitive hosts become infected by eating these crabs/crayfish containing live metacercariae [1].

Regarding host specificity, Paragonimus flukes typically infect a wider spectrum of definitive and second intermediate hosts, whereas specificity for the first intermediate host is usually very strict and vary geographically $[1,3,4]$. Thus, identification of snail hosts in each endemic region is essential for understanding of routes of transmission.

In Vietnam, Paragonimus metacercariae of seven species have been reported in northern and central provinces: $P$. heterotremus, $P$. westermani, $P$. bangkokensis, $P$. harinasutai, $P$. proliferus, $P$. vietnamensis and $P$. skrjabini [5]. Of these, $P$. heterotremus and $P$. westermani are important causative agents for human paragonimiasis in Asian countries. The former species is commonest in northern provinces, and the latter in central provinces [5]. So far, there has been only one report of microcercous cercariae from "Oncomelania" snails in Vietnam, in 2002 [6], at a time when only metacercariae of $P$. heterotremus was found [6, 7]. The cercaria was, therefore, identified as $P$. heterotremus without molecular evidence [6]. However, subsequent surveys have revealed the presence of six additional Paragonimus species, and metacercariae of two to four species has been found in the same area $[5,8]$. Moreover, the taxonomy of the "Oncomelania" snails in Vietnam has been revised and remains uncertain [9-11]. They were re-identified as a new genus Pseudotricula [9]. Since the name Pseudotricula had been assigned previously [10], Dang and Ho [11] renamed their genus as Vietricula. Liu et al. [12] considered that Vietricula snails are closely related to the genus Gammatricula. Thus, data on first intermediate hosts of Paragonimus in Vietnam are scant and unclear. The aim of this study was, therefore, to investigate snail hosts of Paragonimus spp. in Yen Bai and Quang Tri Provinces, where Paragonimus metacercariae are highly prevalent with the dominance of $P$. heterotremus and $P$. westermani, respectively [8]. In this survey, we found cercariae of three Paragonimus species, each in a different snail species. The host specificity and the morphological features of different Paragonimus species in the snail hosts are discussed herein.

\section{Methods \\ Collection and examination of snails}

Freshwater snails were collected in streams in An Lac Commune (Luc Yen District, Yen Bai Province) and Huong Son Commune (Huong Hoa District, Quang Tri Province) (Fig. 1) where high infection rates of crab hosts with Paragonimus metacercariae were found [8]. Snails were morphologically identified following Dang \& Ho [13], and were examined for Paragonimus cercariae using shedding and crushing methods [14]. Snail samples were placed individually in $20 \mathrm{ml}$ wide mouth plastic containers filled with $15 \mathrm{ml}$ of water and left for $24 \mathrm{~h}$. The containers were checked under a stereomicroscope at night and the next morning. If any chaetomicrocercous cercariae were found, they were used for morphological study. Afterwards, all snails were dissected under a stereomicroscope to identify cercariae that did not emerge, and other intramolluscan stages, such as rediae.

Live cercariae and rediae were observed under an Axio Lab A1 microscope (Carl Zeiss, Oberkochen, Germany).

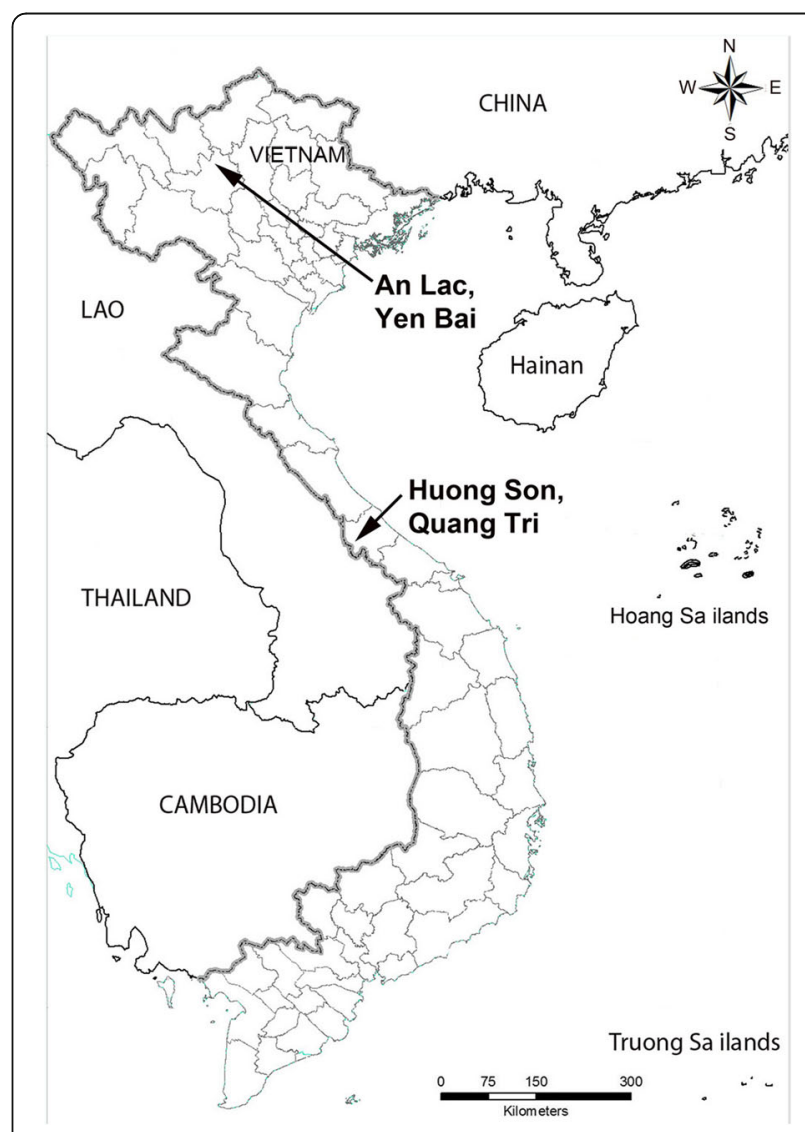

Fig. 1 Geographical locations of sampling sites 
Photographs of the cercariae and rediae were taken using a Axiocam Erc $5 \mathrm{~s}$ digital camera attached to a Axio Lab A1 microscope (Carl Zeiss, Oberkochen, Germany) and ZEN lite software (Carl Zeiss). Cercariae and rediae were drawn using Illustrator CS6. Measurements (in $\mu \mathrm{m})$ of cercariae and rediae were taken. Live cercariae were identified according to Schell [2]. After morphological identification, a single cercaria and tissues from each infected snails were separately preserved in absolute ethanol for molecular identification of cercariae and snail hosts.

\section{Molecular analysis for identification of cercariae and snail hosts}

Genomic DNA of chaetomicrocercous cercariae and snails from 10 infected snails was extracted using a PureLink Genomic DNA Mini Kit (Invitrogen, California, USA) following the manufacturer's protocol. The internal transcribed spacer 2 (ITS2) region of nuclear ribosomal DNA from cercariae was amplified via polymerase chain reaction (PCR) with the primers $3 S$ 5'-CGG TGG ATC ACT CGG CTC GT-3' as a forward primer and A28 5'-CCT GGT TAG TTT CTT TTC CTC CGC-3' as a reverse primer [15]. A portion of the mitochondrial cytochrome $c$ oxidase 1 (cox1) gene of the infected snail species was amplified via PCR with the primers LCO1490 5'-GGT CAA CAA ATC ATA AAG ATA TTG G-3' as a forward primer and HCO2198 5'-TAA ACT TCA GGG TGA CCA AAA AAT YA-3' as a reverse primer [16]. PCR products were purified using a QIAquick PCR Purification Kit (Qiagen, California, USA) and sequencing reactions done using a Big-Dye terminator cycle sequencing kit v3.1 (Applied Biosystems, California, USA). Both forward and reverse strands were sequenced directly by a Genetic Analyzer (Model 3100, Applied Biosystems, California, USA), using the PCR primers as sequencing primers.

Sequences obtained from cercariae and snails were submitted to GenBank with accession numbers LC3605000-LC360505. Basic Local Alignment Search Tool (BLAST) searches in the server of the National Center for Biotechnology Information (NCBI) were used to determine the most similar sequences from named species. The cox 1 sequences of the two triculine snail species showed low similarities to available sequences on GenBank. These sequences were therefore aligned with related sequences, and were used to reconstruct a phylogenetic tree using MrBayes [17]. The substitution model was selected using MrModelTest2 [18]. The model selected was the general time reversal (GTR) model with gamma-distributed rate variation across sites. The data were partitioned by codon position (first, second and third positions). Two parameters of the model (shape of the gamma distribution and substitution rates of the
GTR model) were unlinked across partitions, to allow them to take different values. MrBayes was run for 2,000,000 generations, after which the standard deviation of split frequencies was below 0.01 . Trees were sampled every 500 generations. 'Burn-in' was $25 \%$ of trees. A consensus tree was constructed, including all compatible groups of taxa.

\section{Results}

Identification of snails infected with chaetomicrocercous cercariae

The various snails collected belonged morphologically to Melanoides, Sulcospira and minute snails of the subfamily Triculinae. Snails of the genus Melanoides were few in number and clearly identified as Melanoides tuberculata. In contrast, Sulcospira snails were abundant, occurring at high densities, especially in larger rocky streams with high levels of water and fast flow. They usually attached to the surfaces of stones. The two species of triculine were commonly found attached to fallen leaves in small tributary streams with slow water flow.

Chaetomicrocercous cercariae were not found from M. tuberculata in either studied site or from Sulcospira sp. in Yen Bai Province, but were found from five Sulcospira sp. in Quang Tri, and from four and one triculine snails in Yen Bai and Quang Tri Provinces, respectively.

The sequences obtained from five Sulcospira snails from Quang Tri Province were completely identical with each other. The sequences from four Triculine snails from Yen Bai Province were also identical with each other. The results of BLAST searches showed that the cox1 sequence of the Sulcospira snail from Quang Tri Province was highly similar (99\%) to that of Sulcospira quangtriensis (FJ377265), confirming the identification of this species as $S$. quangtriensis. The $\operatorname{cox} 1$ sequences of Triculinae snails from Yen Bai and Quang Tri Provinces showed the highest similarity (but only 91\% similarity) to Gammatricula snails (AF213342). The samples from Yen Bai and from Quang Tri Provinces differed by $12.6 \%$ and were placed separately in the phylogenetic tree (Fig. 2). The posterior probabilities of groups in which they occurred were rather low. The snail from Quang Tri was grouped with Gammatricula songi with a value of only $53 \%$, the snail from Yen Bai was grouped with Tricula wumingensis with a posterior probability of $56 \%$. The genus Gammatricula is shown as monophyletic, but with a posterior probability of only $27 \%$. The genus Tricula is not monophyletic in this tree. This suggests that the snails from Yen Bai and Quang Tri Provinces belong to different genera of the subfamily Triculinae, but their taxonomic status remains uncertain. We have temporarily labelled them as Triculinae sp. 1 from Yen Bai Province, and Triculinae sp. 2 from Quang 


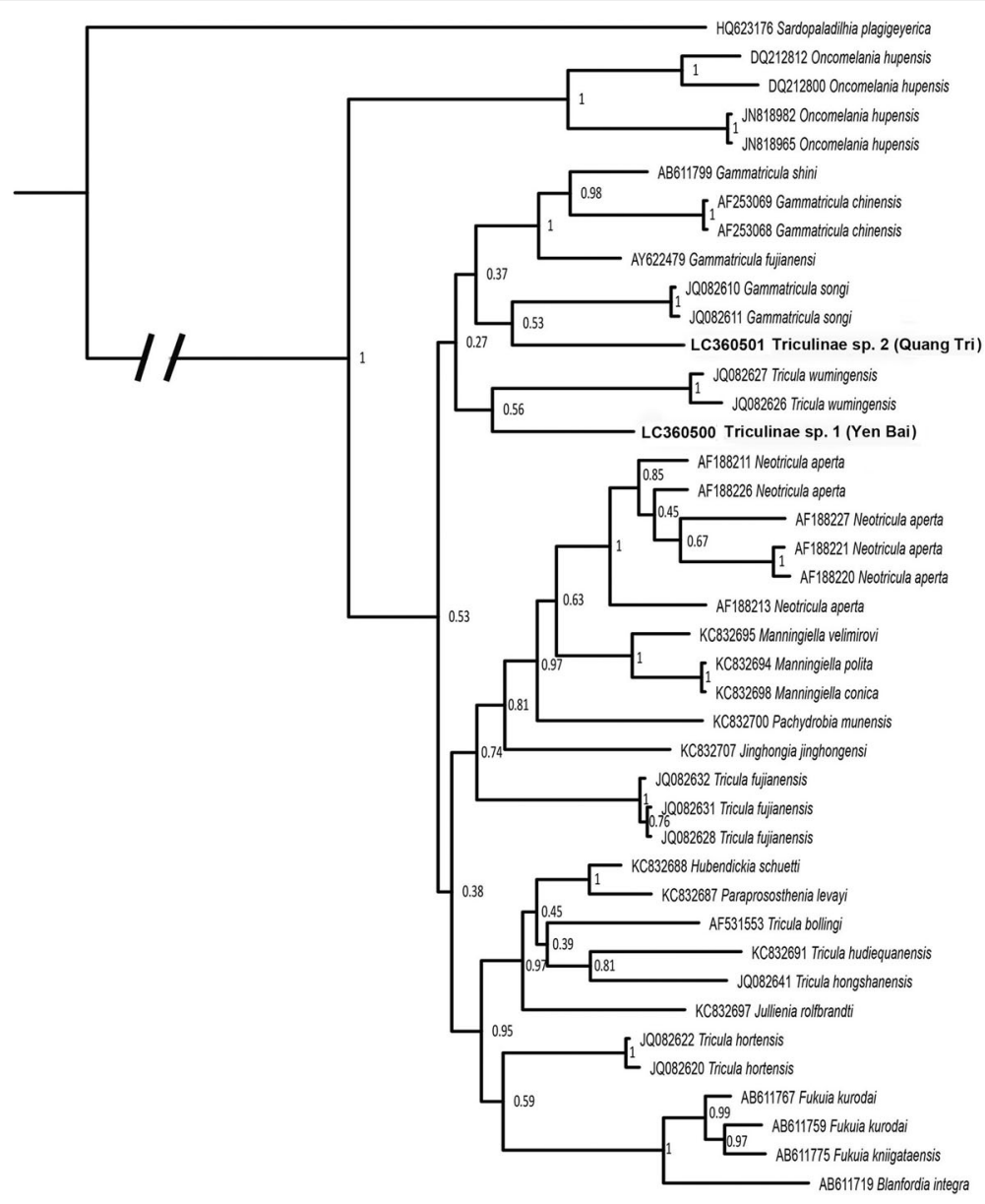

0.03

Fig. 2 Phylogenetic tree reconstructed from cox 1 sequences of triculine snails using Bayesian inference analysis. Numbers at nodes represent posterior probabilities. Samples obtained in this study are printed in bold

Tri Province. The snails infected with chaetomicrocercous cercariae and their habitats are shown in Figs. 3 and 4.

\section{Prevalence and morphology of chaetomicrocercous cercariae from snails}

Infection rates of the snails with chaetomicrocercous cercariae were low, ranging between 0.07-1.0\% (Table 1). In Huong Son Commune, Quang Tri Province, the density of the S. quangtriensis population is very high. Sulcospira quangtriensis collected in the rocky main stream were not positive, but those from a small tributary were infected with chaetomicrocercous cercariae.

The chaetomicrocercous cercariae from different snail species morphologically resemble one another (Fig. 5). In each case, the mature cercariae had a stylet and a short tail, with the measurements presented in Table 2. The body was elongated-oval in shape. The oral sucker at the anterior extremity was accompanied by a long stylet and was larger than the ventral sucker. The latter was round and situated at close to the middle of the body. A total of 14 penetration grand cells were distributed in groups of 3 and 4 cells antero-lateral to the ventral sucker. A large I-shaped excretory bladder was located between the ventral sucker and the end of the body (Fig. 5). These are typical characteristics of Paragonimus cercariae.

In contrast, the daughter rediae collected from different snail species differed from one another in the length of the intestine and the number of cercariae per redia (Fig. 5). The rediae collected from S. quangtriensis possessed a long intestine (about $75 \%$ of the body length) and each redia contained 6-8 cercariae. The rediae from Triculinae sp. 1 and Triculinae sp. 2 each had a short intestine (about 20\% of the redia body length). Each redia from Triculinae sp. 1 contained 10-12 cercariae, double the number (5-6) seen in each redia from Triculinae sp. 2 (Fig. 5). 

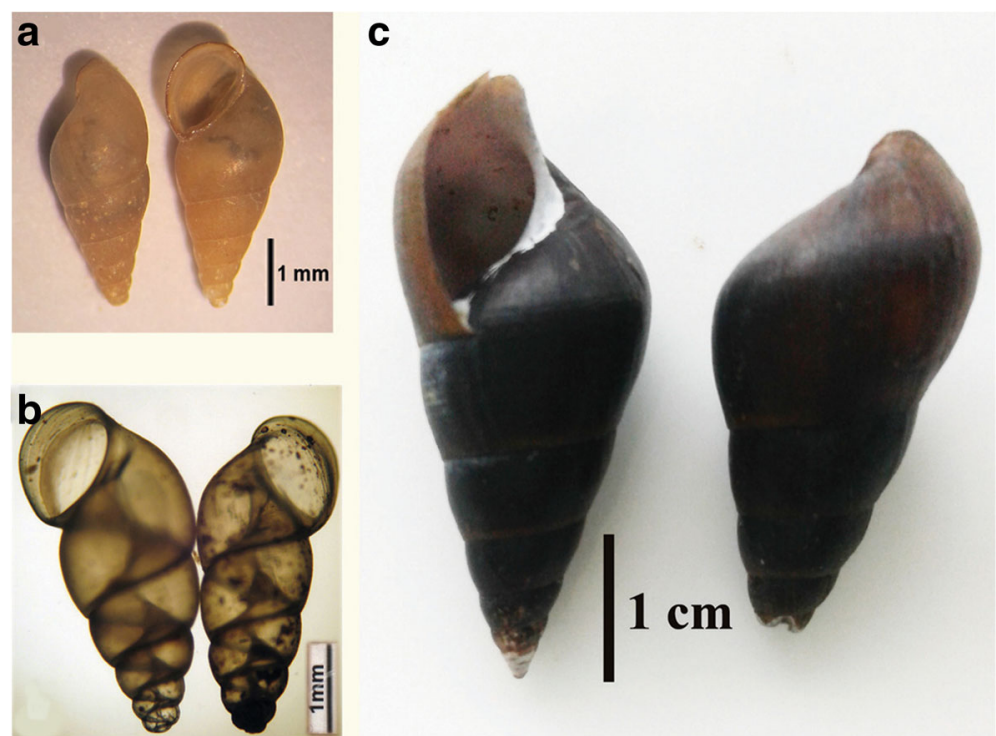

Fig. 3 Freshwater snails infected with Paragonimus cercariae. a Triculinae sp. 1 from Yen Bai. b Triculinae sp. 2 from Quang Tri. c Sulcospira quangtriensis from Quang Tri

\section{Molecular identification of chaetomicrocercous cercariae}

The result of BLAST searches showed that ITS2 sequences of cercariae from snails Triculinae sp. 1 (4 identical sequences from 4 infected snails), Triculinae sp. 2 (1 infected snail) and S. quangtriensis (5 identical sequences from 5 infected snails) were completely (100\%) identical with those of $P$. heterotremus (AB82365), $P$. proliferus (AB663672) and P. westermani (LC144899), respectively.

\section{Discussion}

Previously, cercariae considered to be of $P$. heterotremus were reported from minute snails $(3-4 \mathrm{~mm})$ in northern provinces of Vietnam [6]. As outlined in the introduction, the identity of these snails remains unclear. They

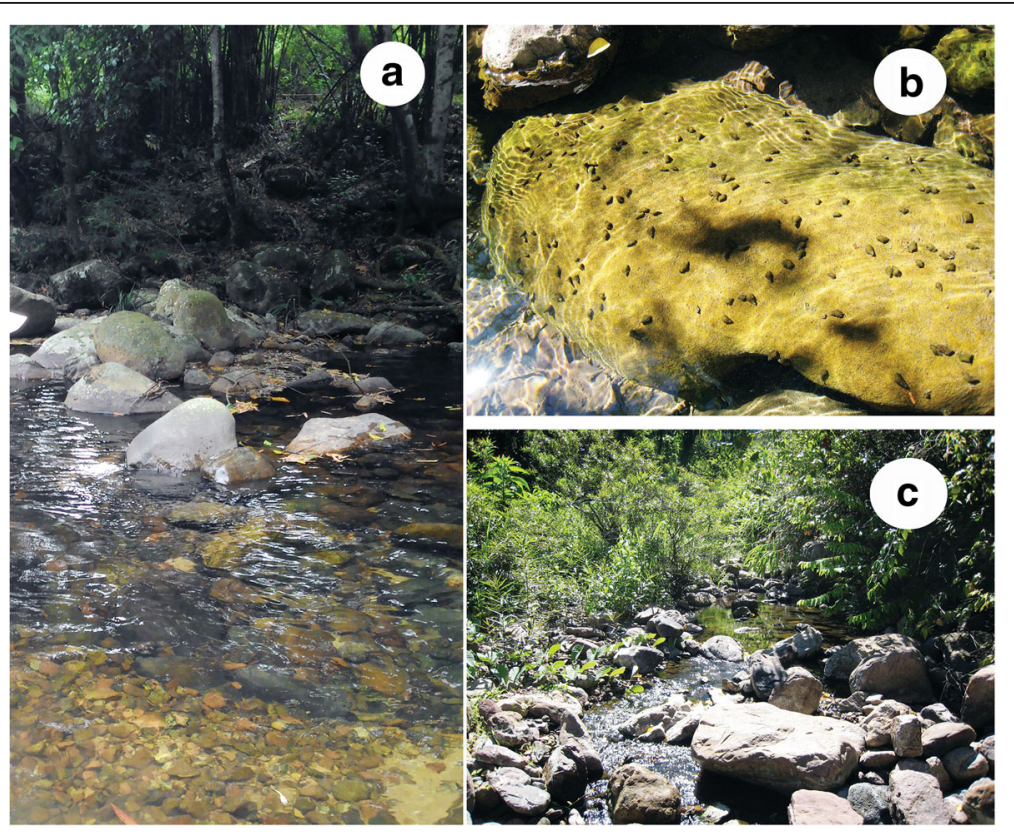

Fig. 4 Habitats of snails in Quang Tri Province. a A rocky main stream with fast water flow. b Sulcospira quangtriensis on a stone of the main stream. c A tributary with slow water flow where Sulcospira and triculine snails live 
Table 1 Prevalence of Paragonimus cercariae in snails

\begin{tabular}{lllll}
\hline Location & Snail species & No. examined & No. infected (\%) & Paragonimus species \\
\hline An Lạc (Yen Bai) & Triculinae sp. 1 & 1200 & $4(0.3)$ & P. heterotremus \\
& Sulcospira sp. & 1000 & 0 & - \\
M. tuberculata & 65 & 1520 & $1(0.07)$ & - \\
Huong Sơn (Quang Tri) & Triculinae sp. 2 & $500^{\text {a }}$ & $5(1.0)$ & P. proliferus \\
& S. quangtriensis & $5000^{\text {b }}$ & 0 & P. westermani \\
& S. quangtriensis & 70 & 0 & - \\
\hline
\end{tabular}

${ }^{a}$ Collected from the small tributary

${ }^{\mathrm{b}}$ Collected from the main stream

were first identified as Oncomelania snails [6], then named as Pseudotricula [9] and re-named as Vietricula [11]. Our results, based on molecular analyses of cox 1 sequences, revealed that the minute Triculinae sp. 1 snails infected with $P$. heterotremus from Yen Bai Province was related to Tricula, and Triculinae sp. 2 snails infected with $P$. proliferus from Quang Tri Province were related to the genus Gammatricula. These might be new snail species. Further detailed studies on anatomy, biology, systematics and genetics are required to confirm the identities and taxonomic status of triculine snails from Vietnam. The remaining snail species, infected with $P$. westermani, was clearly identified as Sulcospira quangtriensis from Quang tri Province.

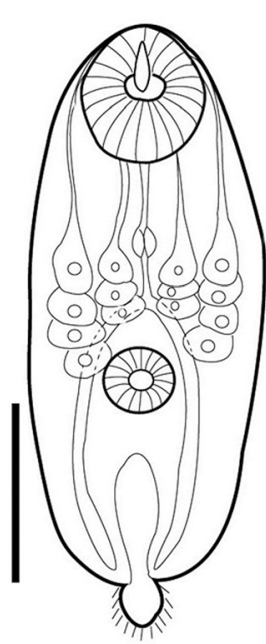

a

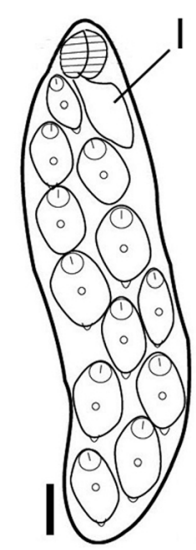

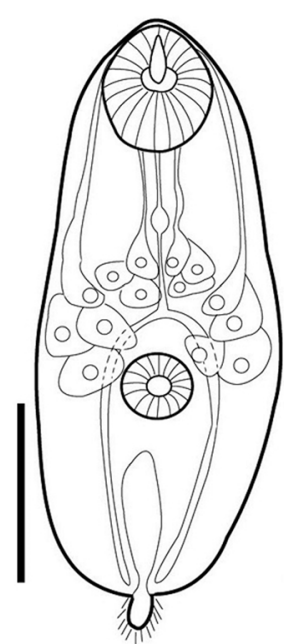

b

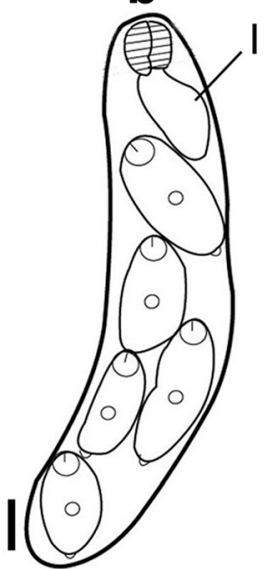

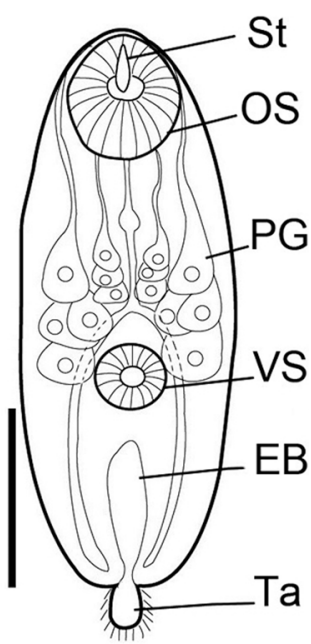

C

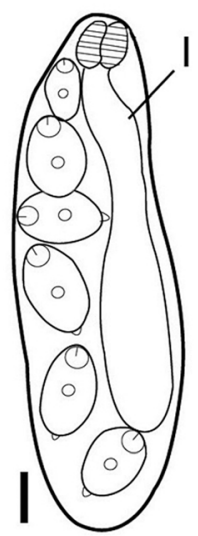

Fig. 5 Cercariae (upper row) and rediae (lower row) of Paragonimus species. a $P$. heterotremus. b $P$. proliferus. c $P$. westermani. Scale-bars: $100 \mu$ m. Abbreviations: OS, oral sucker; VS, ventral sucker; PG, penetration gland; St, stylet; Ta, tail; EB, excretory bladder; I, intestine 
Species of the genus Paragonimus are regarded as exhibiting host specificity for their snail hosts at the superfamily level. Members of the P. westermani complex have only been found in cerithioidean snails but not in the superfamily Rissooidea, within which are the first intermediate hosts of other species (P. skrjabini, $P$. ohirai, P. miyazaki, P. fukienesis, P. kellikotti, P. proliferus, $P$. heterotremus, P. calienesis and P. mexicanus) [4]. There is also regional host specificity; $P$. westermani from the Philippines and Malaysia use thiarid snails while those from Japan, Korea, China and Taiwan exploit pleurocercid snails as the first intermediate hosts [2-4]. In Sri Lanka, P. westermani cercariae were reported from snail Paludomus sp. of the family Paludomidae, also belonging to the superfamily Cerithioidea [19]. In the present study in Vietnam, based on molecular and morphological analyses, cercariae of three Paragonimus species were found, each from a different snail species. Cercariae of $P$. westermani were found from $S$. quangtriensis of the superfamily Cerithioidea, while $P$. heterotremus and $P$. proliferus were found from minute freshwater triculine snails of the superfamily Rissooidea, reinforcing the idea of host specificity at the superfamily level. The snails Sulcospira quangtriensis and Triculinae sp. 2 live in the same water body, but were infected with different Paragonimus species, $P$. westermani and $P$. proliferus, respectively. Also, cercariae of $P$. heterotremus were found from a different snail genus/species. These may suggest host specificity at the genus/species level. The unidentified Sulcospira sp. in Yen Bai Province may act as an intermediate host of $P$. westermani there, and Triculinae sp. 1 may be present somewhere in Quang Tri Province to maintain the life-cycle of $P$. heterotremus, of which eggs have been found in wild cats in this area [20].
The infection rates of snails with Paragonimus cercariae were low, between $0.07-1.0 \%$, although those in crab hosts in the same study area were very high, between $70-100 \%$ [8]. This situation is also found in other countries, such as Malaysia, Japan and China [21-23], and helps to explain why natural first intermediate hosts are known for only a few common species, such as $P$. westermani, $P$. heterotremus and $P$. ohirai [1]. In this study, we identified the natural first intermediate hosts of three species, $P$. westermani, $P$. heterotremus and $P$. proliferus, in Vietnam. Among these, the first two species are common and pathogenetic to humans while $P$. proliferus is a rare species with a low infection rate in crab hosts in Huong Son Commune [8]. In China, the intermediate host of $P$. proliferus was identified as Tricula in experimental infection studies, but the taxonomy of these snails remains confused [1]. Our data clearly show that the natural first intermediate host of $P$. proliferus is a triculine snail, maybe Gammatricula or a closely related taxon.

Morphologically, cercariae of all Paragonimus species, where known, resemble one another closely [1, 2]. Our findings agree, with cercariae of the three Paragonimus species found in this study morphologically indistinguishable. However, they can be distinguished at their redial stages by the length of the intestine and the number of cercariae per redia. These may be useful characteristics for species identification of larval stage of Paragonimus spp. in snail hosts.

\section{Conclusions}

The natural first intermediate hosts of three Paragonimus species were confirmed based on the molecular and morphological identification of both cercariae and snail hosts. Freshwater snails Sulcospira quangtriensis, Triculinae sp. 1 and Triculinae sp. 2 serve as snail hosts for $P$.

Table 2 Measurements ( $\mu \mathrm{m}$ ) of Paragonimus spp. larval stages collected from snails

\begin{tabular}{llll}
\hline Characteristic & P. heterotremus & P. proliferus & P. westermani \\
\hline Cercaria & & & $256-306 \times 104-120$ \\
Body & $240-300 \times 80-110$ & $280-316 \times 100-160$ & $64-80 \times 64-80$ \\
Oral sucker & $50-70 \times 50-60$ & $60-75 \times 60-75$ & $40-48 \times 40-48$ \\
Ventral sucker & $28-30 \times 28-30$ & $35-50 \times 35-50$ & $20-24$ \\
Tail length & $20-25$ & $25-30$ & $40-48$ \\
Stylet length & $40-50$ & $40-50$ & $860-960 \times 200-256$ \\
Redia & & & $64-80 \times 64-80$ \\
Body & $900-980 \times 200-260$ & $1000-1100 \times 220-300$ & $620-640$ \\
Pharynx & $70-86 \times 70-86$ & $80-100 \times 80-100$ & 75 \\
Intestine length & $180-240$ & $200-230$ & $6-8$ \\
Intestine/body length (\%) & 20 & 20 & $5-6$ \\
No. of cercariae per redia & $10-12$ & & 6 \\
\hline
\end{tabular}


westermani, $P$. heterotremus and $P$. proliferus, respectively, suggesting host specificity at the genus/species level. It is difficult to identify cercariae to species based on morphology, but the length of the intestine of the redia and the number of cercariae per redia are valuable characteristics for differentiation between species.

\section{Abbreviations}

BLAST: Basic Local Alignment Search Tool; cox1: Mitochondrial cytochrome c oxidase 1; GTR: General time reversible model; ITS2: Internal transcribed spacer 2; PCR: Polymerase chain reaction

\section{Acknowledgements}

Special thanks are sent to Vietnam National Foundation for Science and Technology Development (NAFOSTED) for supporting this work.

\section{Funding}

This study was funded by Vietnam National Foundation for Science and Technology Development (NAFOSTED) under grant number 106.NN.052016.17 to PND.

\section{Availability of data and materials}

Data supporting the conclusions of this article are included within the article. The datasets used and/or analysed during the current study are available from the corresponding author upon reasonable request. The sequences obtained from cercariae and snails were submitted to GenBank with accession numbers LC3605000-LC360505.

\section{Authors' contributions}

Conceived and designed the study: PND, HVH, LAT, YH, DB and YN. Collected data: PND, HVH, LAT and NVD. Analyzed the data: PND, HVH and LAT. Wrote the paper: PND, LAT, YH, DB and YN. All authors read and approved the final manuscript.

\section{Ethics approval and consent to participate}

Not applicable.

\section{Competing interests}

The authors declare that they have no competing interests.

\section{Publisher's Note}

Springer Nature remains neutral with regard to jurisdictional claims in published maps and institutional affiliations.

\section{Author details}

'Institute of Ecology and Biological Resources, Viet Nam Academy of Science and Technology, Hanoi, Viet Nam. ${ }^{2}$ Graduate University of Science and Technology, Viet Nam Academy of Science and Technology, Hanoi, Viet Nam. ${ }^{3}$ Laboratory of Veterinary Parasitic Diseases, Faculty of Agriculture, University of Miyazaki, Center for Animal Disease Control, University of Miyazaki, Miyazaki, Japan. ${ }^{4}$ College of Marine and Environmental Sciences, James Cook University, Douglas, Australia. ${ }^{5}$ Tropical Diseases Research Centre, Faculty of Medicine, Khon Kaen University, Khon Kaen, Thailand.

Received: 15 February 2018 Accepted: 14 May 2018

Published online: 30 May 2018

\section{References}

1. Blair D, Xu ZB, Agatsuma T. Paragonimiasis and the genus Paragonimus. Adv Parasitol. 1999;42:113-222.

2. Schell SC. How to know the trematodes. Dubuque: W. C. Brown Company Publishers; 1970

3. Davis GM, Chen CE, Kang ZB, Liu YY. Snail hosts of Paragonimus in Asia and the Americas. Biomed Environ Sci. 1994:7:369-82.

4. Wilke T, Davis GM, Gong X, Liu HX. Erhaia (Gastropoda: Rissooidea): phylogenetic relationships and the question of Paragonimus coevolution in Asia. Am J Trop Med Hyg. 2000;62:453-9.

5. Doanh PN, Horii Y, Nawa Y. Paragonimus and paragonimiasis in Vietnam: an update. Korean J Parasitol. 2013;51:621-7.
6. Doanh PN, Le NT, The DT. Distribution of Paragonimus heterotremus and its intermediate hosts in the northwest region of Vietnam. Vietnam J Biol. 2002; 24:14-22. (in Vietnamese with English abstract)

7. De NV, Chau LV, Son DT. Study on the epidemiology, pathology, diagnosis, and treatment of paragonimiasis in northern mountainous provinces of Vietnam. Record of scientfic research works 1996-2000. Nat Inst Malariol Parasitol Entomol. 2000:560-94. (in Vietnamese with English abstract).

8. Doanh PN, Tu AL, Bui TD, Loan TH, Nonaka N, Horii Y, et al. Molecular and morphological variation of Paragonimus westermani in Vietnam with records of new second intermediate crab hosts and a new locality in a northern province. Parasitology. 2016;143:1639-46.

9. Dang NT, Ho TH. The classification of snails belonging to the subfamily Triculinae (Hydrobiidae-Prosobranchia) in Vietnam. Vietnam. J Biol. 2006; 28:8-18.

10. Ponder WF. A new genus and species of aquatic cave living snail from Tasmania (Mollusca: Gastropoda: Hydrobiidae). Pap Proc R Soc Tasmania. 1992:126:23-8.

11. Dang NT, Ho TH. Contribution to the study on Triculinae snail group (Pomatiopsidae - Mollusca) in Tay Nguyen highland, Vietnam. Vietnam 」 Biol. 2010;32:14-8. (in Vietnamese with English abstract)

12. Liu L, Huo GN, He HB, Zhou B, Attwood SW. A phylogeny for the Pomatiopsidae (Gastropoda: Rissooidea): a resource for taxonomic, parasitological and biodiversity studies. BMC Evol Biol. 2014;14:29-59.

13. Dang NT, Ho TH. Freshwater snails in Vietnam. Hanoi: Natural Sciences and Technology Publishing House. 2017; (in Vietnamese).

14. Cort WW. A study of the escape of cercariae from their snail hosts. J Parasitol. 1922:8:177-84.

15. Bowles J, Blair D, McManus DP. A molecular phylogeny of the human schistosomes. Mol Phylogenet Evol. 1995;4:103-9.

16. Folmer O, Black M, Hoeh W, Lutz RA, Vrijenhoek RC. DNA primers for amplification of mitochondrial cytochrome c oxidase subunit I from diverse metazoan invertebrates. Mol Mar Biol Biotechnol. 1994;3:294-9.

17. Huelsenbeck JP, Ronquist F. MrBayes: Bayesian inference of phylogenetic trees. Bioinformatics. 2001;17:754-5.

18. Nylander JAA. MrModeltest v2. Program distributed by the author. Sweden: Evolutionary Biology Centre, Uppsala University; 2004.

19. Iwagami M, Rajapakse RPVJ, Yatawara L, Kano S, Agatsuma T. The first intermediate host of Paragonimus westermani in Sri Lanka. Acta Trop. 2009; 109:27-9.

20. Doanh PN, Hien HV, Tu LA, Nonaka N, Horii Y, Nawa Y. Molecular identification of the trematode Paragonimus in faecal samples from the wild cat Prionailurus bengalensis in the Da Krong Nature Reserve, Vietnam. J Helminthol. 2016;90:658-62.

21. Kim JS. An ecological study of Paragonimus in Malaysia. Korean J Parasitol. 1978;16:47-53.

22. Tomimura T, Sugiyama H, Yokota M. Parasitological survey of the first intermediate host of Paragonimus westermani in Iga area of Mie prefecture, Japan. Nihon Juigaku Zasshi. 1989:51:315-26.

23. Lou HQ, Hu Y, Jin YJ, Yu XT, Wang L, He XY, et al. Investigation on the hosts with natural infection and species identification in Jinhua prefecture of Zhejiang Province. Chin J Parasitol Parasit Dis. 2011;29:348-52.

\section{Ready to submit your research? Choose BMC and benefit from:}

- fast, convenient online submission

- thorough peer review by experienced researchers in your field

- rapid publication on acceptance

- support for research data, including large and complex data types

- gold Open Access which fosters wider collaboration and increased citations

- maximum visibility for your research: over $100 \mathrm{M}$ website views per year

At BMC, research is always in progress.

Learn more biomedcentral.com/submissions 